\title{
STEP-BY-STEP MODELING OF WIND ENERGY CONVERSION SYSTEMS FOR TRANSIENT STABILITY STUDIES
}

\author{
Hasan Shaaban, Tamer A. Kawady, and Abdallah El-sherif \\ Electrical Engineering Department, Faculty of Engineering, \\ Minoufiya University, Shebin El-Kom, Egypt
}

\begin{abstract}
Owing to the increasing penetration of renewable energy resources in the electric grids, the need for systematic studies of the impact of wind power on voltage, synchronous (angle) and frequency stability of the grid is encouraged. Unlike the massive literatures for stability issues with conventional energy resources, the corresponding research efforts for Wind Energy Conversion Systems (WECS) are still highly demanded. In this paper, a comprehensive methodology for realizing an efficient, versatile and accurate modeling for grid-integrated WECS for transient stability studies is explored. Details for representing the wind aerodynamics, drive trains, wind generators in addition to other conventional synchronous generators with its control mechanisms are outlined. The presented study is conducted with the known IEEE 3-generator, 9-bus power system network as a simulation example. Some explanation cases are illustrated examining the system voltage, angle and frequency stability.

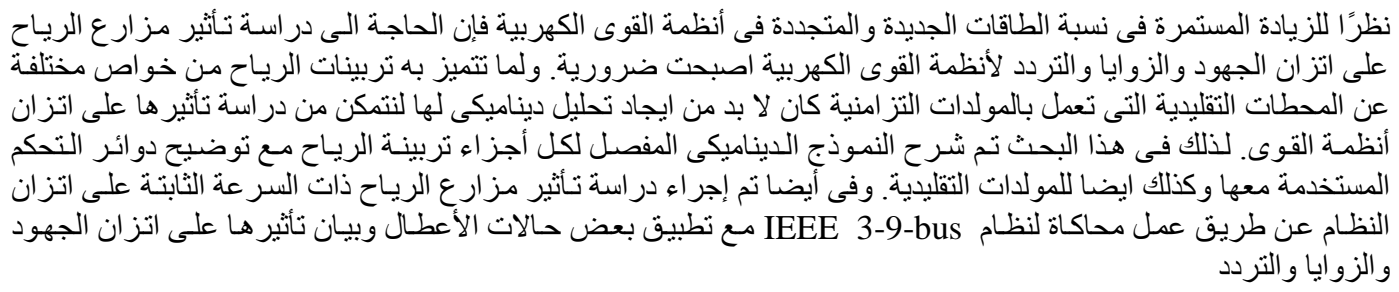

Keywords: Transient stability, Wind Energy Conversion System, Pitch angle, Fixed speed wind turbine, Synchronous stability and Voltage stability.

\section{INTRODUCTION}

Owing to the rapid increase of the global population, uneven distribution of resources and the nonrenewable nature of fossil fuels, the importance of renewable energy resources is obvious. Among the various renewable resources, wind power is assumed to have the most favorable prospects. Such energy resources are increasingly considered as not only a means to reduce the $\mathrm{CO} 2$ emissions generated by traditional fossil fuel fired utilities but also a promising economic alternative in areas with appropriate wind speeds [1]-[3]. As a result, wind energy is the world's fastest growing energy source with an average growth over the past 5 years of $26 \%$ and a foreseeable penetration of $12 \%$ of the global electricity demand by 2020. In the USA, in particular, most of the American states has "Renewable Portfolios Standard" ranging from 10$20 \%$ of total installed capacity by 2020 [4].

On the other hand; as the penetration of wind energy resources increases, the impact of wind turbine generators on power system dynamic behavior exaggerates. It is therefore very important and imperative to study their effects on the stability of power system networks and to emphasize the methodologies to avoid their massive problems. These problems, when occur, impact significantly the performance of the overall grid and may result in total (or partial) blackouts.

As the integration level of wind energy is increasing, concerns regarding the stability of the already existing power system are becoming of utmost importance. So far, nearly all the transient stability studies of the grid-connected generators under various fault types have been dominated by the conventional synchronous generators. However, the dynamic response characteristics of wind turbine generators are different from those conventional synchronous ones. As a result, impacts of wind turbine generators on power system dynamic behavior will be different as well. Therefore, it is very important and imperative to carry out the power 
system angle, voltage and frequency stability studies considering the different models of the wind generators in conjunction with their dedicated control mechanisms.

The increasing penetration of wind farms into power system was recently investigated in the literatures [5]-[7]. Generally, wind generators are primarily classified as either fixed speed (SFIGs) or variable speed ones (DFIGs). Although SFIGS are distinctive with some certain unique features (brushless and rugged construction, low cost, maintenance free and operational simplicity), consuming massive amounts of reactive power is a serious feature. Accordingly, a capacitor bank must be provided close to the generator terminal in order to compensate for this reactive power consumption so that the generator does not burden the grid. As reported in [8], [9], the transient characteristics of wind farms during the three phase short circuit conditions were highlighted. The dynamic modeling of DFIG suitable for transient stability analysis is presented in [10]-[13]. Further efforts were presented exploring the detailed performance of their IGBTbased inverters with their practical considerations for stability issues [14], [15]. Modeling of the mechanical drive train was analyzed in [16].

In the paper, a step-by-step modeling of WECS integrated with electric grid is presented for performing transient stability studies. The known IEEE system with three generators, nine-bus, six lines, and three load centers was employed as a simulation example. One of the system generators having $27 \%$ of the system total generated active power is replaced by a single FSIG equivalent. The system transient stability studies are carried out considering the effect of AVR and speed governor systems for the synchronous generators and the pitch angle control for the FSIGs. Effects of short circuits and wind speed variations are explored.

\section{WIND TURBINE MODELING}

Figure 1, shows the schematic diagram of a fixed speed wind turbine generator, which consists of three main parts: the rotor, drive train and the generator. The dynamic models of these three parts are given as follows.

\subsection{Rotor Model}

It is well known that, the mechanical power extracted from the wind is given by [17], [18]

$$
\mathrm{p}_{\mathrm{m}}=\frac{1}{2} \rho \mathrm{AC}_{\mathrm{p}}(\lambda, \beta) \mathrm{V}_{\mathrm{w}}{ }^{3}
$$

where $\rho$ is the air density $(\mathrm{kg} / \mathrm{m} 3), A$ is the sweep area of the blades $(\mathrm{m} 2), \mathrm{Vw}$ is the wind speed $(\mathrm{m} / \mathrm{s})$ and $\mathrm{Cp}$ the power coefficient, which represents the rotor efficiency (captured power/wind power), and it depends on the tip speed ratio $(\lambda)$ and the blade pitch angle $(\beta)$. A generic equation of $\mathrm{Cp}$ is given as [19]:

$$
\mathrm{C}_{\mathrm{p}}(\lambda, \beta)=\mathrm{c}_{1}\left[\frac{\mathrm{c}_{2}}{\lambda_{\mathrm{i}}}-\mathrm{c}_{3} \beta-\mathrm{c}_{4}\right] \mathrm{e}^{\frac{-\mathrm{c}_{5}}{\lambda_{\mathrm{i}}}}+\mathrm{c}_{6} \lambda
$$

Where, C1, C2,...., C6 are constant parameters depending on the wind turbine type. Tip-speed ratio" $\lambda "$ is given by,

$$
\lambda=\frac{2 \pi \mathrm{nR}}{\mathrm{V}_{\mathrm{w}}}
$$

where, $\mathrm{R}$ is the blade radius and $\mathrm{n}$ is the rotational speed. $\lambda$ can be then mathematically approximated as,

$$
\lambda i=\left[\frac{1}{\lambda+0.08 \beta}-\frac{0.035}{\beta^{3}+1}\right]^{-1}
$$

The pitch angle controller is typically used for limiting the generated power to the rated value for wind speed exceeding the rated wind speed. The pitch angle control mechanism using a PI regulator is depicted in Fig. 2.

\subsection{The Drive Train Dynamic Model}

The most common way to model the drive train is to treat it as two masses connected together by a springs, as shown in Fig.3.

Referring to the aforementioned figure, the dynamic model of the drive train is given as [17],

$$
\begin{aligned}
& \frac{\mathrm{d} \omega_{\mathrm{t}}}{\mathrm{dt}}=\frac{1}{\mathrm{~J}_{\mathrm{t}}}\left(\mathrm{T}_{\text {wind }}-\mathrm{T}_{\mathrm{m}}-\mathrm{D}_{\mathrm{t}} \omega_{\mathrm{t}}\right) \\
& \frac{\mathrm{d} \omega_{\mathrm{g}}}{\mathrm{dt}}=\frac{1}{\mathrm{~J}_{\mathrm{g}}}\left(\mathrm{T}_{\mathrm{m}}-\mathrm{T}_{\mathrm{em}}-\mathrm{D}_{\mathrm{g}} \omega_{\mathrm{g}}\right)
\end{aligned}
$$

$\mathrm{T}_{\mathrm{m}}=\mathrm{K}_{\mathrm{tg}} \int\left(\omega_{\mathrm{t}}-\omega_{\mathrm{g}}\right) \mathrm{dt}+\mathrm{D}_{\mathrm{tg}}\left(\omega_{\mathrm{t}}-\omega_{\mathrm{g}}\right)$

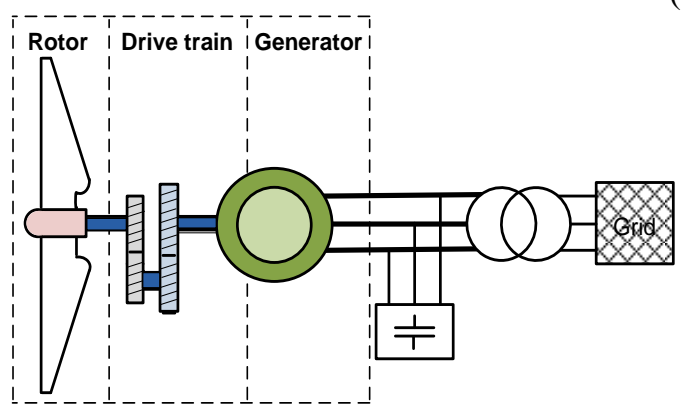

Fig. 1 schematic diagram of FSIG wind turbine system

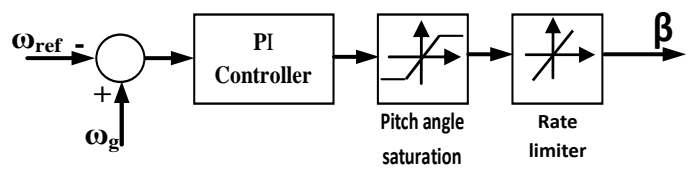

Fig. 2 Control scheme of the pitch regulated wind turbines 


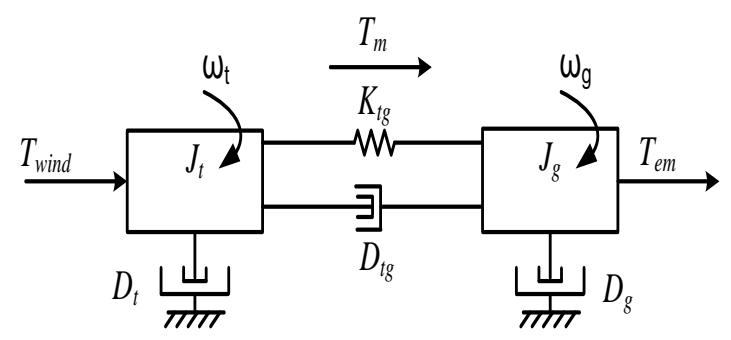

Fig. 3 The drive train modeling schematic

where $\omega_{\mathrm{t}}$ and $\omega_{\mathrm{g}}$ are the turbine and generator speeds respectively, $\mathrm{J}_{\mathrm{t}}$ and $\mathrm{J}_{\mathrm{g}}$ are the turbine and generator inertias respectively, $\mathrm{T}_{\mathrm{m}}$ is the transmission torque between the considered two masses, $\mathrm{K}_{\mathrm{tg}}$ and Dtg are the stiffness and damping of the mechanical coupling.

\section{INDUCTION GENERATOR STEADY STATE AND DYNAMIC MODELS}

Referring to Fig.4, the IG steady-state equivalent circuit can be described with the illustrated equivalent circuit. Both the generator slip and input reactive power can be determined after solving of the two loop currents.

Fig. 5, shows the IG transient equivalent circuit, which is used in the paper, to carry out the power system transient stability studies [20].

Referring to Fig. 5, the IG third-order transient state model is described as,

$$
\begin{aligned}
& \frac{d e_{d}^{\prime}}{d t}=s \frac{1}{T_{o}^{\prime}}\left[t i\left(X-X-{ }_{s}^{e}\right)_{q s}\right]-\omega_{s} e_{q}^{\prime} \\
& \frac{d e_{q}^{\prime}}{d t}=s \frac{1}{T_{o}^{\prime}}\left[-i\left(X-X+{ }_{s}^{\prime}\right)_{d s}\right]-\omega_{s} e_{d}^{\prime} \\
& T_{m}-T_{g}=J_{g} \frac{d \omega_{g}}{d t}
\end{aligned}
$$

In Equations (8), (9) and (10), e`d and e' $q$ are the generator direct-axis and quadrature -axis internal voltage components. iqs and ids are the quadratureaxis and direct-axis currents respectively. Tm and $\mathrm{Tg}$ are the generator mechanical and electrical torque. $\omega s$ and $\omega g$ are the synchronous and generator speed respectively. $\mathrm{Jg}$ is the generator inertia. T'o is the transient open circuit time constant and $\mathrm{X}$ 's is the transient reactance are computed as,

$$
\mathrm{T}_{\mathrm{o}}^{\prime}=\frac{\mathrm{X}_{2}+\mathrm{X}_{\mathrm{m}}}{\omega_{\mathrm{s}} \mathrm{R}_{2}} \quad, \quad \mathrm{X}^{\prime} \mathrm{s}=\mathrm{X}_{1}+\frac{\mathrm{X}_{\mathrm{m}} \mathrm{X}_{2}}{\mathrm{X}_{2}+\mathrm{X}_{\mathrm{m}}}
$$

where $\mathrm{R} 2$ and $\mathrm{X} 2$ are the rotor resistance and reactance respectively. $\mathrm{X} 1$ is the stator reactance and $\mathrm{Xm}$ is the magnetizing reactance. The generator electrical torque is calculated as,

$$
\mathrm{T}_{\mathrm{g}}=\mathrm{e}_{\mathrm{d}}^{\prime} \mathrm{i}_{\mathrm{ds}}+\mathrm{e}_{\mathrm{q}}^{\prime} \mathrm{i}_{\mathrm{qs}}
$$

The IG active and reactive powers $\mathrm{Pg}$ and $\mathrm{Qg}$ are expressed by,

$$
\begin{aligned}
& \mathrm{P}_{\mathrm{g}}=\mathrm{V}_{\mathrm{ds}} \mathrm{i}_{\mathrm{ds}}+\mathrm{V}_{\mathrm{qs}} \mathrm{i}_{\mathrm{qs}} \\
& \mathrm{Q}_{\mathrm{g}}=\mathrm{V}_{\mathrm{ds}} \mathrm{i}_{\mathrm{qs}}-\mathrm{V}_{\mathrm{qs}} \mathrm{i}_{\mathrm{ds}}
\end{aligned}
$$

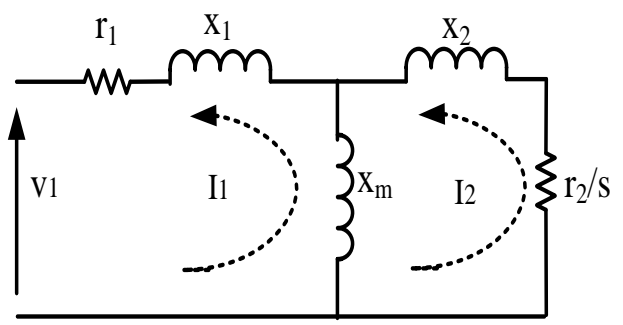

Fig. 4 The induction generator (IG) steady- state equivalent circuit

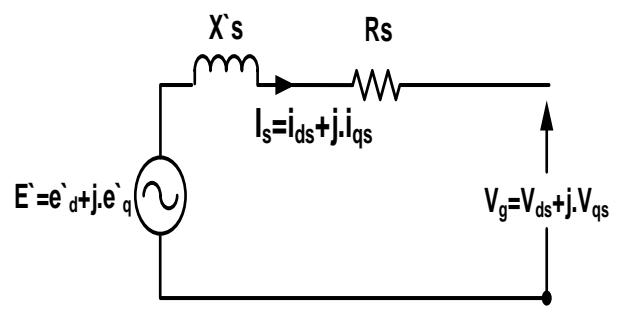

Fig. 5 The induction generator transient equivalent circuit

\section{SELECTED POWER SYSTEM NETWORK}

The well known IEEE standard 3-generator, 9-bus power system, shown in Fig. 6, is considered for preparing the required simulation examples [21]. It is assumed that each of the system generators is equipped with the automatic voltage regulator (AVR) and speed governor as described in Fig. 7 and 8 [22] considering $\mathrm{KA}=25, \mathrm{TA}=0.05, \mathrm{Kg}=50$ and $\mathrm{Tg}=5$.

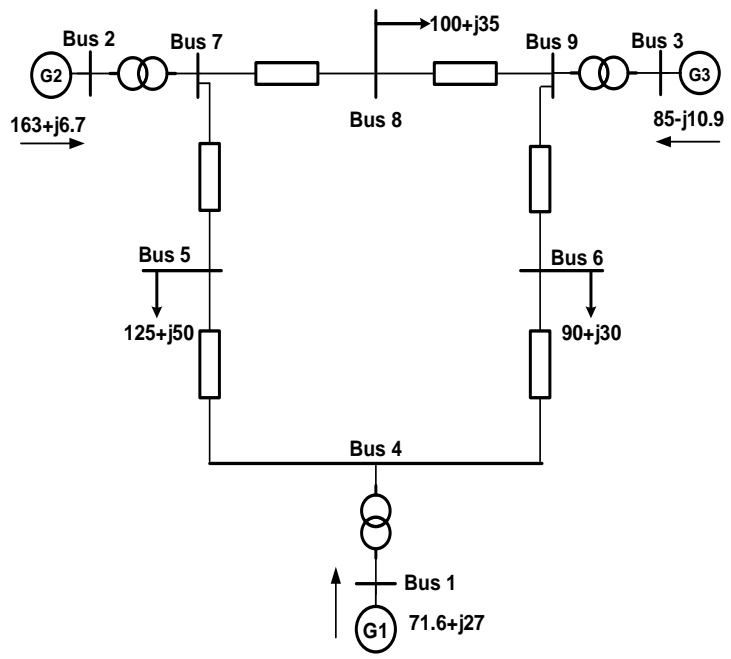

Fig. 6 One line diagram of the selected IEEE 9-bus system 


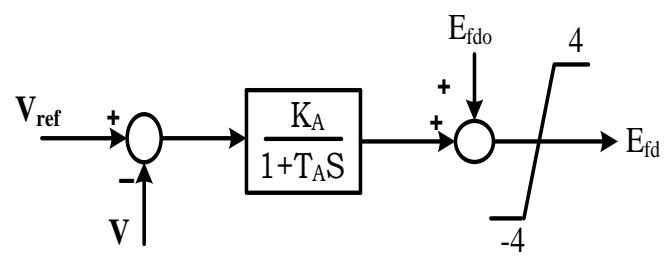

Fig. 7 IEEE Type-AC1A Excitation system representation

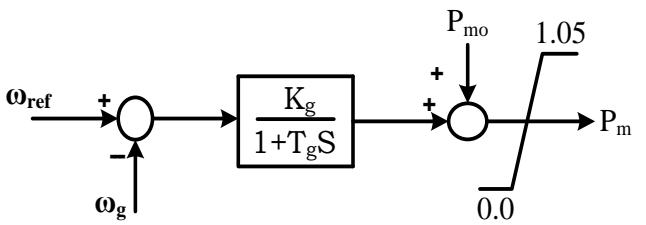

Fig. 8 speed governor system representation

\section{SIMULATED EXAMPLES FOR TRANSIENT STABILITY ISSUES}

In order to emphasize the paper aim, a preliminary stability study was performed with the selected IEEE 9-bus system utilizing the developed simulation platform. Effects of considerable amounts of WECS in conjunction with conventional synchronous generators are highlighted. One of these conventional ones (connected at bus 3) is replaced by a FSIG equivalent generator representing the overall wind farm. Also, the FSIG output active power is assumed to equal $0.85 \mathrm{pu}$ (the removed generator output power). This power is equal to about $27 \%$ of the system total generated power. Referring to Fig. 4 the FSIG loop current equations are solved. It is found that the generator steady state slip $\mathrm{So}=-0.0181$, and its input reactive power equals 0.4512 pu. Hence, after carrying out the system load flow study, it is chosen a capacitor of the reactive power $0.38624 \mathrm{pu}$ to be connected with the FSIG.

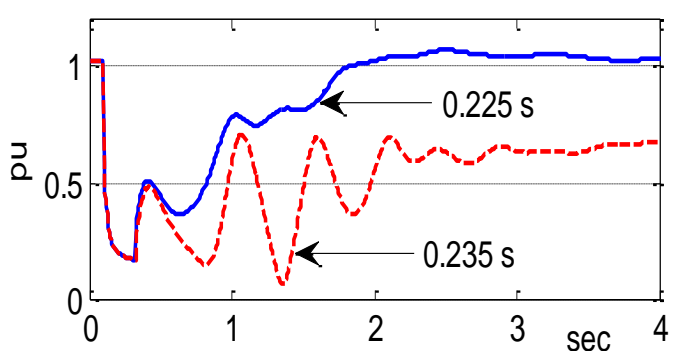

Fig. 9.a Wind farm terminal voltage

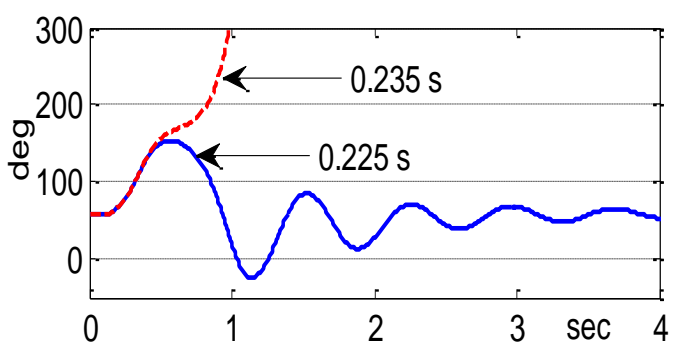

Fig. 9.b Synchronous machines relative angle $\delta 21$

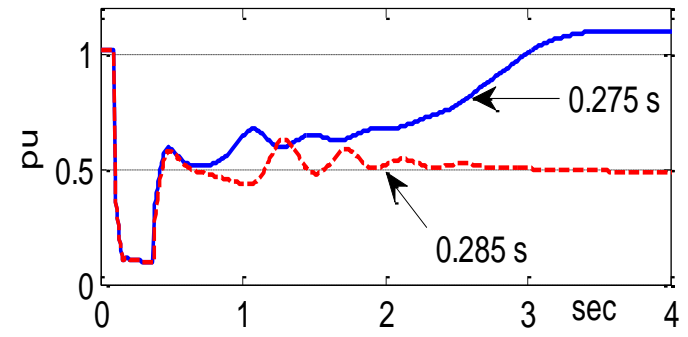

Fig. 10.a Wind farm terminal voltage

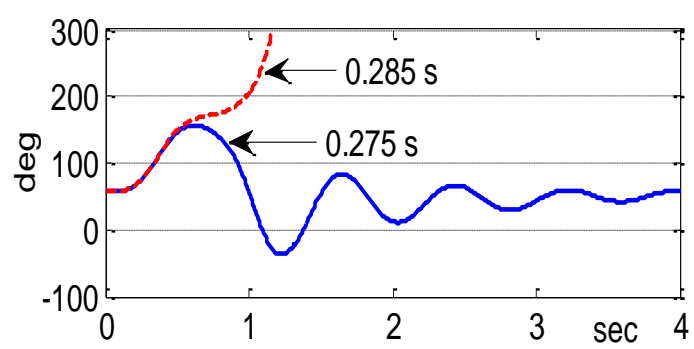

Fig. 10.b Synchronous machines relative angle $\delta 21$

Representing each of the system two synchronous generator by the well known three-axis model, and using Eqs 1-14, the considered system transient stability studies are carried out considering different case studies as described in the following subsections.

\section{Case study 1: Stability studies considering a 3- phase short circuit fault.}

The short circuit fault was initiated at $0.10 \mathrm{sec}$. at bus 8 . It is found that both the system synchronous (angle) and voltage stability are lost, as shown in Figs. 9.a and 9.b. The system can maintain its stability when the fault is removed after elapsing a time interval not larger than $0.225 \mathrm{sec}$. from the fault instant. Figs 10.a and 10.b show the wind farm voltage V3 and the synchronous generators relative angle $\delta 21$ when the fault occurred at the midpoint of the line 8-9.

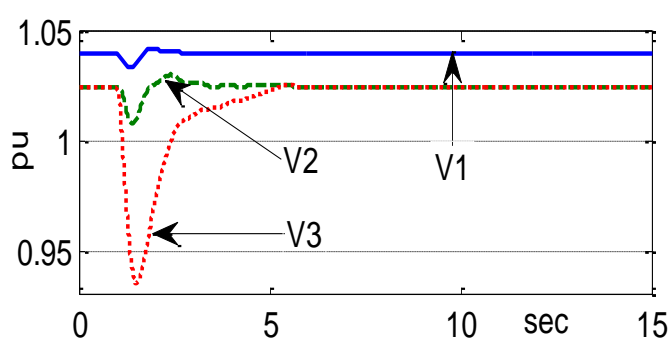

Fig. 11.a Terminal voltage of the system synchronous and induction generators

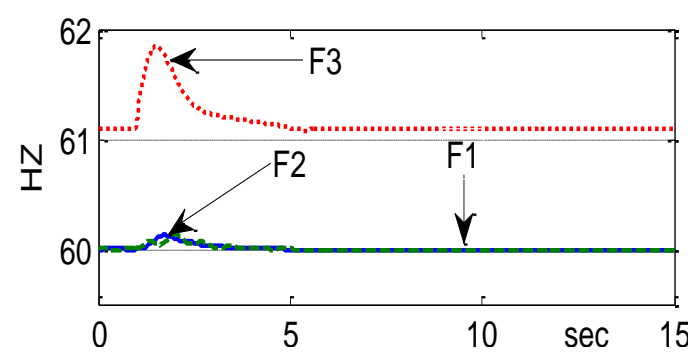

Fig. 11.b Frequency of the system generators 


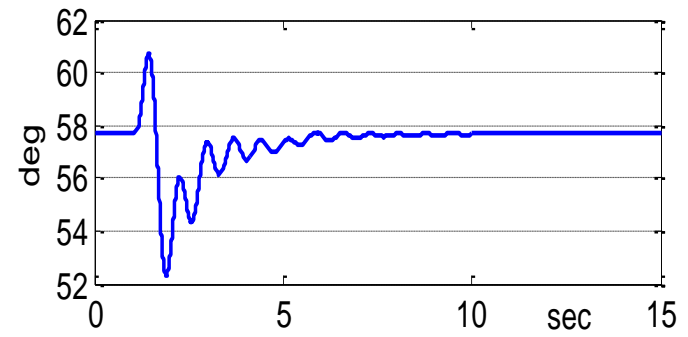

Fig.11.c Synchronous machine relative angle $\delta 21$

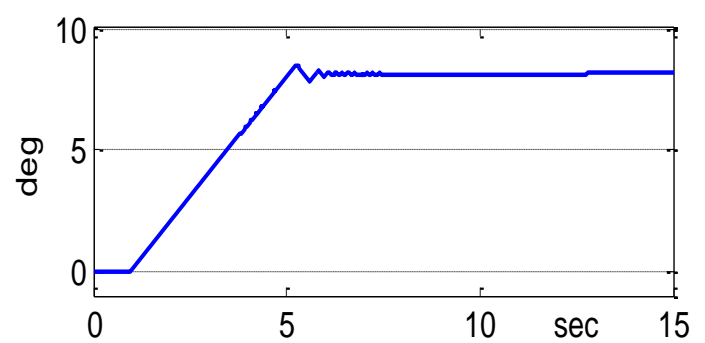

Fig.11.d Profile of pitch angle

As concluded from the results, the system can maintained its both voltage and synchronous stability, if the faulted line is isolated before 0.285 sec. from the fault instant. On the other hand, the original system (equipped with three synchronous generators only) has the critical times for isolating the faults of the first and second locations of 0.25 and $0.3 \mathrm{sec}$. respectively.

\section{Case study 2: Stability studies for an increase of wind speed.}

In this test case, the wind speed was increased from $12 \mathrm{~m} / \mathrm{sec}$. (the rated wind speed) to $15 \mathrm{~m} / \mathrm{sec}$. Then, the system stability computations were carried out. As revealed from the results, the system maintained its stability as shown in Fig 11.a, to 11.d. Owing to the pitch angle control mechanism, the FSIG input mechanical power was kept constant, and hence the generator speed did not change.

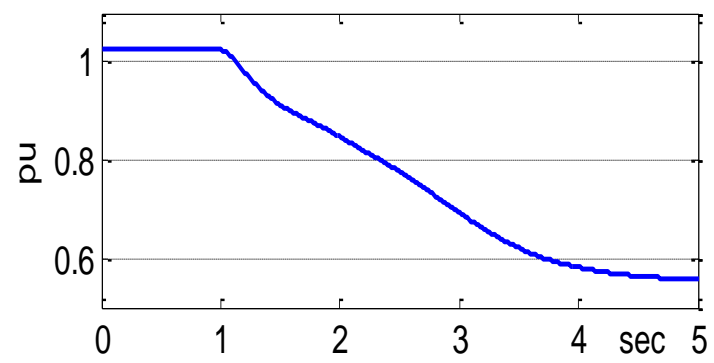

Fig.12.a Wind farm terminal voltage

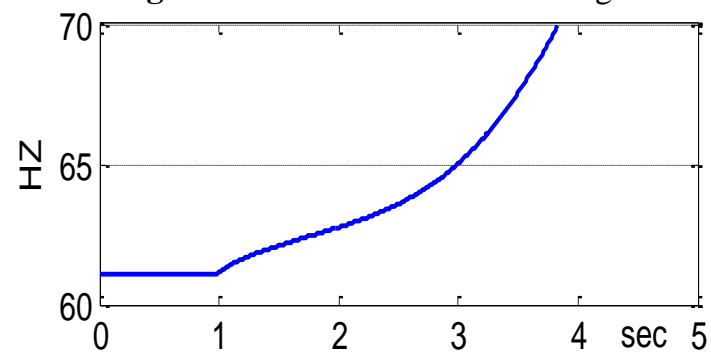

Fig.12.b Frequency of the induction generator
The stability computations were then repeated neglecting the effect of the pitch angle control. It is found that after the wind speed increasing, the system will lose its voltage and frequency stability, as shown in Figures 12.a and 12.b.

Case study 3: Stability studies assuming a 3-phase short circuit fault after an increase in the wind speed.

The wind speed was increased from 12 to 15 $\mathrm{m} / \mathrm{sec}$. and a 3-phase short circuit fault was applied at bus 8 after $0.1 \mathrm{sec}$. Referring to Figs 13.a, 13.b and 13.c, both the system voltage and frequency stability were maintained when the fault duration time is less than $0.15 \mathrm{sec}$.

These presented simulation examples may raise different conclusions. The critical time value for removing a short circuit at one of the system buses or isolating a faulted line, are about $90 \%$ of those for the original power system. This essentially means that replacing a synchronous generator by an FSIG may deteriorate the system stability. For an increase in the wind speed which is followed by a 3-phase short circuit at one of the system buses, the critical time for removing the fault is equal to about $65 \%$ of that for the short circuit fault under the normal wind speed. This means that increasing the wind speed deteriorates the system stability. Further investigations are being carried out for both SFIGs and DFIGs as will be demonstrated in our next publications.

\section{IMPACT OF WECS PENETRATION LEVEL}

For a certain 3-phase short circuit at bus 8, different lower values of the injected wind active power were tested, then the system stability computations were repeated at each condition. This computational scenario helps to visualize the pinpoint the effectively allowable penetration level of wind power for the considered simulated system. As revealed from Figures 14.a, 14.b and 14.c the system can maintain its voltage, frequency and angle stability when the wind farm injected active power decreased from $0.85 \mathrm{pu}$ to $0.81 \mathrm{pu}$.

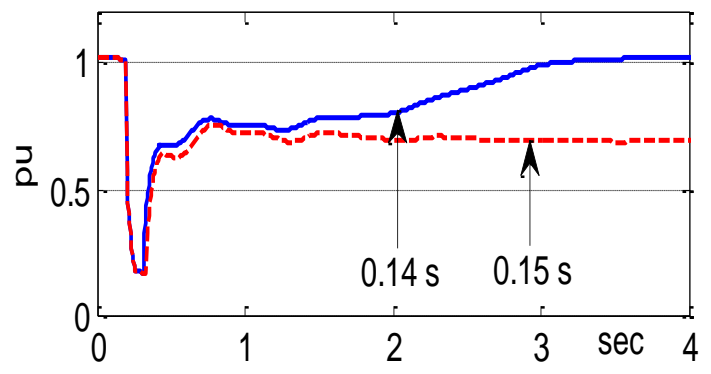

Fig.13.a Wind farm terminal voltage 


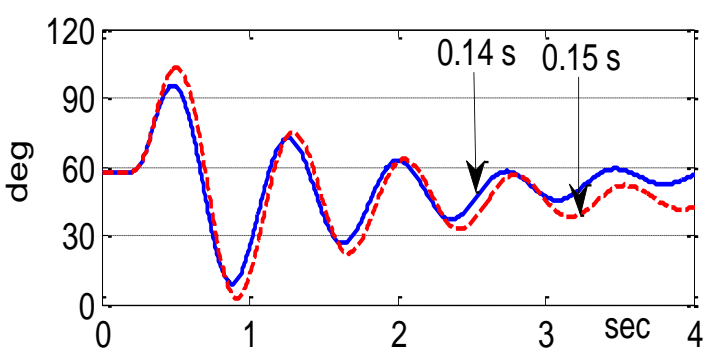

Fig.13.b Synchronous machines relative angle $\delta 21$

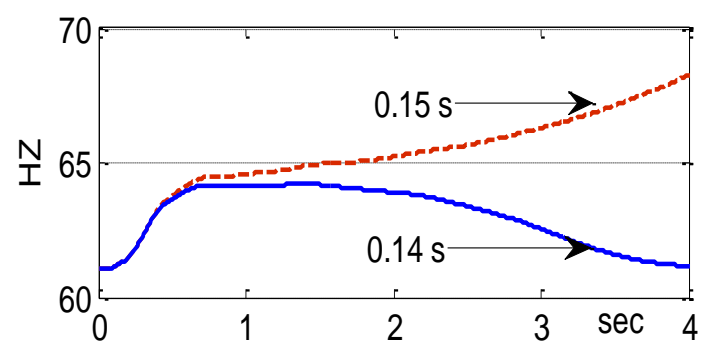

Fig.13.c Frequency of the induction generator

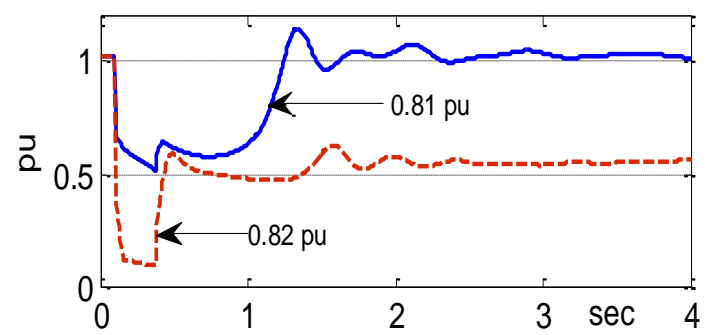

Fig.14.a Wind farm terminal voltage

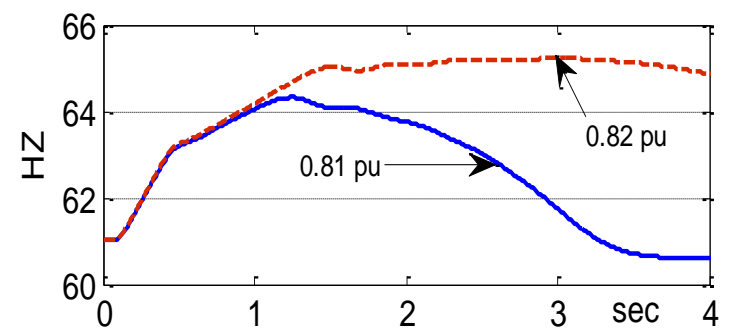

Fig.14.b Frequency of the induction generator

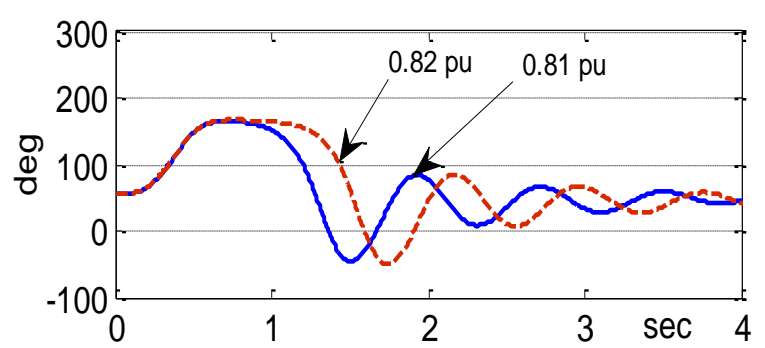

Fig.14.c Synchronous machines relative angle $\delta 21$

\section{CONCLUSIONS}

In this paper, a detailed and simplified modeling of WECS for analyzing transient stability issues is presented. Description of the aerodynamic part of the wind turbine, mechanical train and wind generators were presented. Scenarios for analyzing the transient stability of power networks with considerable amounts of WECS penetration levels are visualized. Replacing one of the synchronous generators of the
IEEE standard system with 3-generator, 9-bus, 3load centers by an equivalent FSIG, the corresponding transient stability studies of the system were carried out. In these studies, a 3-phase short circuit was applied. Then, the effects of pitch angle control and wind speed increasing were evaluated.

\section{REFERENCES}

[1] Juan M. Rodríguez, José L. Fernández, Domingo Beato, Ramón Iturbe, Julio Usaola, Pablo Ledesma, and José R Wilhelmi " Incidence on Power System Dynamics of High Penetration of Fixed Speed and Doubly Fed Wind Energy Systems: Study of the Spanish Cas" IEEE TRANSACTIONS ON POWER SYSTEMS, VOL. 17, NO. 4, NOVEMBER 2002

[2] H.R. Najafi, F.V.P. Robinson, F. Dastyar and A.A. Samadi "Small- disturbance Voltage Stability of Distribution Systems with Wind Turbine implemented with WRIG", Power Engineering, Energy and Electrical Drives, 2009. POWERENG '09. International Conference on, 18-20 March 2009, Lisbon, 2009.

[3] Libao Shi, Shiqiang. Dai, Yixin Ni, Liangzhong Yao, and Masoud Bazargan "transient stability of power system with high penetration of DFIG based wind farms", Power \& Energy Society General Meeting, 2009. PES '09. IEEE, 26-30 July 2009, Calgary, Canada, 2009.

[4] Luis M. Fernandez, Jose Ramon Saenz and Francisco Jurado "Dynamic models of wind farms with fixed speed wind turbines", Renewable Energy, Elsevier, Volume 31, Issue 8, July 2006, Pages 1203-1230, 2006.

[5] M.V.A. Nunes, J.A.P. Lopes, H.H. Zurn, U.H. Bezerra and R.G. Almeida, "Influence of the variable-speed wind generators in transient stability margin of the conventional generators integrated in electrical grids," IEEE Trans. on Energy Conversion, vol. 19, pp. 692-701, Dec. 2004.

[6] J. Usaola, P. Ledesma, J.M. Rodriguez, J.L. Fernandez, D. Beato, R. Iturbe and J.R Wilhelmi, "Transient stability studies in grids with great wind power penetration. Modelling issues and operation requirements," in IEEE Power Engineering Society General Meeting, 2003; pp. 1534-1541.

[7] D. Gautam, V. Vittal, T. Harbour, "Impact of increased penetration of DFIG-based wind turbine generators on transient and small signal stability of power systems," IEEE Trans. on Power Systems, vol. 24, pp. 1426-1434, Aug. 2009.

[8] M.S. Vicatos, J.A. Tegopoulos, "Transient state analysis of a doubly-fed induction generator 
under three phase short circuit," IEEE Trans. on Energy Conversion, vol. 6: pp. 62-68, Mar. 2003.

[9] Senjyu, N. Sueyoshi, K. Uezato, H. Fujita, T. Funabashi, "Transient stability analysis of induction generator using torque-time characteristic," in The Fifth International Conference on Power Electronics and Drive Systems, Singapore, 2003, vol.1: pp. 760-765.

[10] L.B. Shi, Z. Xu, J. Hao and Y.X. Ni, "Modelling analysis of transient stability simulation with high penetration of gridconnected wind farms of DFIG type," Wind Energy, vol. 10, pp. 303-320, Mar. 2007.

[11] L.B. Shi, S.Q, Dai, Y.X. Ni, Y.D. Zhao, M. Bazargan, "Transient stability of power system with high penetration of DFIG based wind farms, " in IEEE Power \& Energy Society General Meeting, Calgary, Canada, 2009.

[12] S.M. Muyeen, H.A. Mohd, R. Takahashi, T. Tamura, Y. Tomaki, A. Sakahara and E. Sasano, "Transient stability analysis of wind generator system with the consideration of multi-Mass shaft model," in International Conference on Power Electronics and Drives Systems, 2005, pp. 511-516.

[13] Libao Shi, Member, IEEE, Shiqiang. Dai, Yixin $\mathrm{Ni}$, Senior Member, IEEE, Liangzhong Yao, and Masoud Bazargan, " Transient Stability of Power Systems with High Penetration of DFIG Based Wind Farms"

[14] J.Kretschmann, H.Wrede, Member, IEEE, S. Mueller-Engelhardt, I. Erlich, Senior Member, IEEE, " Enhanced Reduced Order Model of Wind Turbines with DFIG for Power System Stability Studies", First International Power and Energy Coference PECon 2006, November 2829, 2006, Putrajaya, Malaysia.

[15] Istvan Erlich, Senior Member, IEEE, Jörg Kretschmann, Jens Fortmann, Member, IEEE, Stephan Mueller-Engelhardt, and Holger Wrede, Member, IEEE, " Modeling of Wind Turbines Based on Doubly-Fed Induction Generators for Power System Stability Studies", IEEE TRANSACTIONS ON POWER SYSTEMS, VOL. 22, NO. 3, AUGUST 2007

[16] J.B. Ekanayake, L. Holdsworth, X. Wu and N. Jenkins, "Dynamic modeling of doubly fed induction generator wind turbines," IEEE Trans. on Power Systems, vol. 18, pp. 803-809, May 2003.
[17] Y. Mishra, S. Mishra, Fangxing Li and Z. Y. Dong "Small Signal Stability Analysis of a DFIG Based Wind Power System With Tuned Damping Controller Under Super/Sub Synchronous Mode of Operation" Energy Conversion, IEEE Transactions on, Dec. 2009, Vol. 24, Issue 4, pp. 972 - 982, 2009.

[18] Juan M. Rodríguez, José L. Fernández, Domingo Beato, Ramón Iturbe, Julio Usaola, Pablo Ledesma, and José R Wilhelmi " Incidence on Power System Dynamics of High Penetration of Fixed Speed and Doubly Fed Wind Energy Systems: Study of the Spanish Cas" IEEE TRANSACTIONS ON POWER SYSTEMS, VOL. 17, NO. 4, NOVEMBER 2002

[19] K.C. Divya, P.S. Nagevdra Rao "Models for Wind Turbine Generating Systems and Their Application in Load Flow Analysis", Electric Power Systems Research, Vol. 18, No. 3 October 2005, pp. 249-262.

[20] Kundur P. "Power system stability and control", Text Book, McGraw-Hill Companies, Inc., New York,

[21] P. M. Anderson and A. A. Fouad, "Power System Control and Stability", Text Book, John Wiley and Sons, New York, 2003.

[22] S.M. Muyeen , Junji Tamura and Toshiaki Murata, " stability augmentation of a grid connected wind farm", Text Book, SpringerVerlag London Limited, 2009.

\section{Acknowledgement}

The authors are expressing their gratitude to the Egyptian "Science and Technology Development Fund (STDF), for funding this work.

\section{APPENDEX}

Table 1, Data for induction generator aggregated model

\begin{tabular}{|l|l|}
\hline Parameter & Description value \\
\hline Rated voltage, $\mathrm{V}$ & $0.69 \mathrm{KV}$ \\
\hline Stator resistance, $\mathrm{R}_{1}$ & $0.0062 \mathrm{pu}$ \\
\hline Stator leakage reactance, $\mathrm{X}_{1}$ & $0.136 \mathrm{pu}$ \\
\hline Rotor resistance, $\mathrm{R}_{2}$ & $0.02 \mathrm{pu}$ \\
\hline Rotor leakage reactance, $\mathrm{X}_{2}$ & $0.112 \mathrm{pu}$ \\
\hline Magnetizing reactance, $\mathrm{X}_{\mathrm{M}}$ & $3.91 \mathrm{pu}$ \\
\hline Inertia constant, $\mathrm{H}$ & $6.3 \mathrm{MWs} / \mathrm{MVA}$ \\
\hline Number of poles & 4 \\
\hline
\end{tabular}

